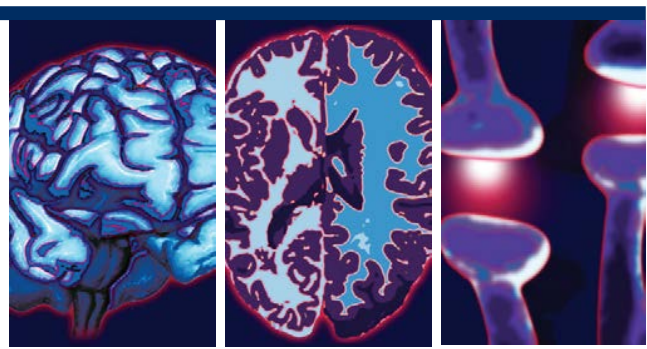

\title{
The Experience of Playing Located Based Game among Young Adults: Findings from a Focus Group Study
}

\author{
Ka Huen YIP
}

\begin{abstract}
\section{Background}

In Hong Kong, a lot of young adults are smartphone users. There are a number of health consequences in the physical realm, psychological area, and social aspects caused by game addiction of smartphone users. Game playing with smartphones is popular among young phone users. A location-based game (LBG) has recently received big attention from the young players. As such, this report is intended to explore the Hong Kong young adults' perceptions on playing LBG, Pokémon GO about their physical discomfort, and joy in playing the game.
\end{abstract}

\section{Methods and Findings}

We conducted 3 focus group discussions, held between January and April 2017, on this LBG (e.g., intention to try, harmfulness, and leisure) with a total of 17 young adults (age from 1825 years old). We analysed the discussions using a thematic approach. Participants generally reported positive perceptions on playing the LBG, particularly because of their visual appeal in a reality situation. Some negative perceptions were reported. All participants believed the LBG would be at risk with increasing number of negative outcomes if participants were not handling the indulgence in the game well. Participants also commented that this game could be gateways to augmented reality with LBG.

\section{Conclusion}

Young adults welcome the LBG and are willing to experiment with Pokémon GO. Playing the LBG may alter the young adults' attitude and behavioural intention among their social interaction to pursue a common goal, physical activity and daily living behaviour.

\section{Keywords}

Located Based Game, Pokémon GO, Young adults

\section{Introduction}

In the late $20^{\text {th }}$ century, the use of smartphones became popular. With the advancement in technologies, the prices of smartphones have become affordable and indispensable to a large proportion of the public. Smartphones nowadays are readily equipped with advanced mobile operating system including the features of a handheld personal computer system [1]. The most prevalent group of smartphone users in Hong Kong is the group of young people. Approximately $96.1 \%$ of persons aged 10 and over owned a smartphone in 2015 [2]. These smartphones are usually with multi-functions, from phone call to internet service, social networking, and gameplay [3-5]. 
Based on previous studies and knowledge, smartphone gameplay has a relatively controversial function as there is a general perception that it will bring immense joy but at the same time a negative impact to the health of the players. Location-based games (LBG), the new generation of technology, offer a pervasive game, allowing game players to evolve and progress according to the player's location. Pokémon GO, introduced by Nintendo - a Japanese Corporation well known for inventing online games, has immersed augmented reality with LBG. The Pokémon GO players will engage themselves in virtual environment through the use of their smartphones and pursue to search for and capture cartoon characters. The characteristic of location-based online game is the connection of virtual environment with real life locations. Different cartoon characters will appear in the virtual environment in different real life locations. It appeals to young people. So they will be tempted to download the game (or alternatively named as the app) and start walking around in their neighbourhood to look for the cartoon characters. This game not only has the ability to arouse and capture the interests of a large population, but also incentivizes and encourages the game players to perform physical exercise while strolling around the geolocation. However, it is noticed that long hours of persistently playing smartphone games may cause adverse impact on one's mental or physical well-being.

The above brings a very interesting as well as worrying concern: would playing LBG bring good or adverse health impact to young people? There are several studies reporting a number of health consequences regarding game addiction in the physical realm [6-14]; in the psychological area [6,10-11,15-19], and/or in social aspects [10-11,20-22]. For instance, a study by Schilling (2016) and Griffin (2016) stated that it could help to relieve depression [23]. Other studies indicated that playing LBG could help to solve the obesity problem as the playing of the game would demand bodily movement and physical exercise [24,25]. A press release from the University of Leicester (2016) also reported that playing LBG could have the benefit of easing the type 2 diabetics' burden by engaging in physical mobility such as walking and standing [26].

Prolonged period and excessive playing of LBG might cause the players to develop into LBG addiction $[27,28]$. According to the Diagnostic and Statistical Manual for Mental Disorders (DSM-5) and a numbers of studies indicating the diagnostic criteria of addiction according to playing LBG [29-31], there are five different behavioural observations resulted from excessive internet use including computer addiction, net compulsions, information overload, cyber sexual addiction, and cyber-relational addiction [32]. The prolonged period and excessive playing LBG is easily and perhaps obviously seen as cyberrelated addiction.

While playing LBG continuously over a long period of time might not seem to be a problem for all players, addiction to it, on the other hand, is always detrimental to the health of the player involved $[33,34]$ : "Healthy excessive enthusiasms add to life, whereas addictions take away from it" [35]. Excessive gameplay with the benefit of promoting the health state of individuals would be considered a positive effect on individuals' health [36]. Thus, while there are both advantages and disadvantage in playing LBG, the benefits so derived will often be more perceivable than the problems associated with it.

The playing of LBG has proven that social interactions may help to distract patients who are also LBG game players from pain and facilitate their healing $[37,38]$. It also helps the game players to cope with psychological disorders like depression and social anxiety [23,39-41]. Most significantly, Pokémon GO has the particular feature of motivating men and women of all ages to move around, increase their physical activity and reduce sedentary behavior [42-44]. There is report that due to the location-based technology, players have walked 2500 steps daily in playing the game [45].

There is limited study to report the addiction of playing LBG on the socially withdrawn young people and also on the safety concerns in playing LBG as the players would need to stroll around in the community to hunt for the cartoon characters. There is similar concern perceived by the public in Hong Kong regarding the benefit and adverse impact that could be generated from addiction in playing the online games like LBG.

Excessive playing LBG should be avoided, particularly if it is for the purpose of leisure playing. In this respect, this study will possibly serve as one of the pioneer studies exploring the experience of Hong Kong young people playing the LBG and the effect on their health social aspects of life. The current study was targeted to young people as they are the group that is obviously and easily associated with playing online games. 


\section{Methods}

\section{- Methods}

Participants that have been recruited in this study are those playing the LBG, Pokémon GO; and they are recruited using snowball sampling method. There are 3 recruitment criteria: (a) Hong Kong residents and recruited in Hong Kong; (b) current Pokémon GO players at the time of recruitment; (c) able to understand and speak in Cantonese. Eligible participants are those between 18 and 25 years old.

\section{- Data collection}

Focus group discussions were held between January and April 2017. We developed a discussion guide (Table 1) based on literature review of playing LBG, internet or online games, and related physical and psychosocial health perceptions [46-54]. The guide included topics such as perceptions of playing LBG (e.g., harmfulness relative to playing Pokémon GO and social interaction) and experience of playing LBG. The first author (Yip), who had received training in conducting and analysing focus group discussions, moderated each semi-structured focus group discussion. Participants completed a short questionnaire on demographic information, written consent, and playing LBG before the discussion. The length of discussion was about 45-60 minutes.

\section{- Ethical consideration}

This study was approved by the Committee on the use of Human and Animal Subjects in Teaching and Research, Tung Wah College, prior to commencement. Seventeen participants were recruited and agreed to take part in the study. They were informed that if they felt uncomfortable during the interviews, they were allowed to leave the study at any time. In order to protect the interviewees' privacy, the study used anonymous identifications, and all videotaped data were secured.

\section{- Data analysis}

We videotaped and transcribed verbatim all focus group discussions, and analysed them using a thematic approach [55], aided by NVivo 11 qualitative software [56]. The fifth author (Kong), sixth author (Kwai) and seventh author (Lee) reviewed all transcripts and derived a set of themes and subthemes from the discussions, and the fourth and eighth authors (Wong and Ho) independently reviewed all transcripts and the appropriateness of the themes and subthemes derived by the first author. Disagreements on themes and subthemes were resolved through discussions. The fifth, sixth, and seventh authors then coded all the transcripts by categorizing relevant statements in the transcripts under themes and subthemes [57]. The third author then reviewed the coded statements. Disagreements on the codes were resolved through discussions. Two other authors (Yip and Ko) then verified the results of the analysis after reading through all transcripts. We also examined the findings in terms of the length of time of playing the LBG, the trainer level acquired by the player in the game and the money the player spent on the game.

\section{Results}

\section{- Demographic characteristics}

We conducted three focus group discussions involving a total of 17 participants (12 males and five females), in 2 groups with 5-6 participants per group. Participants were between 18 and 25 years old (Table 2). The majority of the participants were students (59\%) while others were under employment (35\%). One had acquired trainer level five, one had trainer level between 11-15, four had trainer level between 16-20, four had trainer level between 21-25, six had trainer level between 26-30, and one had trainer level 31-35 (Table 2). About 82\% (14) of the participants reported they never spent money to play Pokémon GO, two spent US\$13-

Table 1: Focus group question guide.
\begin{tabular}{|l|l|}
\hline 1. & Question \\
\hline 2. & Can you describe one experience of playing Pokémon GO in the outdoors? \\
\hline 3. & Can you describe what it feels like when playing Pokémon GO? \\
\hline 4. & To which part of the game do you feel the most attracted? \\
\hline 5. & What are the differences between your social life before and after you played Pokémon GO? \\
\hline 6. & Can you share the interaction with friends, family or other strangers since you played the game, based on your own experience? \\
\hline 7. & If there was no Pokémon GO now, how would you utilize that time period? \\
\hline 8. & What are your comments regarding the weight of the pros and cons of Pokémon GO? \\
\hline
\end{tabular}


Review Ka Huen YIP

\begin{tabular}{|c|c|c|c|c|c|c|}
\hline \multirow{3}{*}{ Playing LBG in the last 6 months } & \multirow{2}{*}{\multicolumn{2}{|c|}{\begin{tabular}{|l|} 
All \\
$n=17$
\end{tabular}}} & \multirow{2}{*}{\multicolumn{2}{|c|}{$\begin{array}{l}\text { Male } \\
n=12\end{array}$}} & \multirow{2}{*}{\multicolumn{2}{|c|}{$\begin{array}{l}\text { Female } \\
n=5\end{array}$}} \\
\hline & & & & & & \\
\hline & $n$ & $\%$ & $n$ & $\%$ & $n$ & $\%$ \\
\hline \multicolumn{7}{|l|}{ Length, $\mathrm{m}$} \\
\hline 1 & 1 & 6 & 0 & 0 & 1 & 20 \\
\hline 2 & 5 & 29 & 4 & 33 & 1 & 20 \\
\hline 3 & 0 & 0 & 0 & 0 & 0 & 0 \\
\hline 4 & 2 & 12 & 2 & 17 & 0 & 0 \\
\hline 5 & 2 & 12 & 2 & 17 & 0 & 0 \\
\hline 6 & 7 & 41 & 4 & 33 & 3 & 60 \\
\hline \multicolumn{7}{|l|}{ Trainer level } \\
\hline $1-5$ & 1 & 6 & 1 & 8 & 0 & 0 \\
\hline $6-10$ & 0 & 0 & 0 & 0 & 0 & 0 \\
\hline $11-15$ & 1 & 6 & 0 & 0 & 1 & 20 \\
\hline $16-20$ & 4 & 24 & 2 & 17 & 2 & 40 \\
\hline $21-25$ & 4 & 24 & 3 & 25 & 1 & 20 \\
\hline $26-30$ & 6 & 34 & 5 & 42 & 1 & 20 \\
\hline $31-35$ & 1 & 6 & 1 & 8 & 0 & 0 \\
\hline \multicolumn{7}{|l|}{ Time spend per day, $\mathrm{h}$} \\
\hline$<1$ & 6 & 35 & 3 & 25 & 3 & 60 \\
\hline $1-3$ & 10 & 59 & 8 & 67 & 2 & 40 \\
\hline $4-6$ & 1 & 6 & 1 & 8 & 0 & 0 \\
\hline \multicolumn{7}{|l|}{ Money spending, US\$ } \\
\hline 0 & 14 & 82 & 10 & 84 & 4 & 80 \\
\hline $1-12$ & 0 & 0 & 0 & 0 & 0 & 0 \\
\hline $13-64.5$ & 1 & 6 & 0 & 0 & 1 & 20 \\
\hline 64.6-129 & 1 & 6 & 1 & 8 & 0 & 0 \\
\hline$>129$ & 1 & 6 & 1 & 8 & 0 & 0 \\
\hline \multicolumn{7}{|l|}{ Venue in playing LBG } \\
\hline 1 & 2 & 11.8 & 1 & 8.33 & 1 & 20 \\
\hline 2 & 2 & 11.8 & 1 & 8.33 & 1 & 20 \\
\hline 3 & 1 & 5.9 & 1 & 8.33 & 0 & 0 \\
\hline 4 & 4 & 23.5 & 3 & 25 & 1 & 20 \\
\hline 5 & 5 & 29.4 & 3 & 25 & 2 & 40 \\
\hline 6 & 0 & 0 & 0 & 0 & 0 & 0 \\
\hline All locations & 3 & 17.6 & 3 & 25 & 0 & 0 \\
\hline
\end{tabular}

129 , and one spent more than US\$129 to play Pokémon GO (Table 2). The time duration that the players have been playing Pokémon GO was one to six (a mean of 4) months. The playing time per day was one to three (mean of 2.3) hours.

The experiences of playing LBG were categorized into five main themes: (a) an innovative gaming mode, (b) walk to the next destination, (c) virtual-reality navigator, (d) link together, and (e) stand on or lost.

\section{- An innovative mode of gaming}

All the participants typically described the attraction to play the game was the retrieval of their childhood memories of watching the Pokémon cartoon on TV. They derived the fun of playing the game by actually participating in the pursue of Pokémon in the virtual world through the use of their smartphones. In essence, it is a connection of their fond memories through the virtual world in the real life locations.

Pokémon GO appealed to the participants as it was one of the most popular TV series in their childhood. Half of the participants shared the same reason for engaging in playing the game.

With a smiling face, Tommy said, "Pokémon held a special place in my heart."

Alex engaged in lots of mobile games and stated, "While you're playing Pokémon GO, you're required to have the first-hand experience in the game - when walking to the certain location yourself, then Pokémon will appear in front of you 


\author{
- at that moment, you seem you were Ash Ketchum \\ (main character in Pokémon animation) in the \\ Pokémon movie."
}

Four participants took that Pokémon was real in their living world because the cartoon characters would appear on the street when the smartphone camera was on; then they would need to, in the virtual world, throw a ball at it for catching it. Peter had a similar response: "Compared with other games, it's more realistic and close to the reality. During gaming, none other than Pokémon $G O$ could be realised and incorporated in your real life."

\section{- Walk for the next destination}

All participants agreed that LBG encouraged them to increase exercising when participating in this game as it compels them to leave their house, changes their daily walking and living routines for the purpose of hunting the cartoon characters. Most of the participants thought this game may act as an incentive for those who are socially withdrawn. Yin commented that an autistic child was compelled to step out the door with her mum through the game mode, and this child showed a happy appearance when she got a new character of the game.

John said, "I think the attractive point is that it requires you to play outside; whereas, for most of gaming, you usually stay at home. But this game forces you out to somewhere for hunting Pokémon."

Torres emphasized the reason for walking was that "I can't hatch the eggs while I'm taking the public transport. It'd be difficult to detect new Pokémon, so I chose to walk."

Wilson had a similar response: "I really enjoy running with my friends. We always rush for an unknown Pokémon in extremely limited time. And it made me sweat everywhere, including my hands, forearms, and even underarms."

Although everyone has a regular pattern in doing things in their daily routine, some of the participants struggled with changing their daily routines. Tommy explained that he preferred to get off the public transport early or go on foot to certain place as these are the simplest ways to hatch a Pokémon egg or get the Pokéstop. This urged Tommy to increase his exercise amongst different age groups, particularly with his parents, when he was usually typically physically inactive.

Tommy said shyly, "Take my family as an example. My parents would go out, too, which was really shocking. I've never seen my dad do something like that. There were many other middle-aged people on the street. Despite their intention to just play the game, it turned out that they exercised a lot more."

\section{n Virtual-reality navigator}

Numerous participants reported that Pokémon GO can shape the connection between the virtual world and real life. Players will need to look for Pokémon in the community in Hong Kong. Some legendary Pokémon characters may be found in specific famous locations in different countries of the world. As a result, all participants would actually have opportunities to navigate some place new in the local community or even to other countries.

Alex had a gasp of surprise at his experience and said, "I hang out more around the neighbourhood because of Pokémon GO. So I discovered a place that I don't know by the picture of the Pokéstop and found out that it's just nearby my home."

John was an active player who expressed his enjoyable experience in hunting Pokémon everywhere and aimed to be one of the world's master trainers. He emphasized that it could be a useful tool for knowing and obtaining in-depth understanding of the geographical and cultural environment of the community. John stated, "I visited Signal Hill, Lai Chi Kok Park, as well as Star Ferry Pier, and familiarized myself with the surroundings of the places that I travelled. Thus, I would not only focus on the game nature itself, but would also go out more and find out more about the nearby district."

\section{n Link together}

All participants commented that this game evoked social interaction among players and presented their experiences in sharing a common goal, gathering with like-minded people, following the crowd, increasing peer interaction and promoting an inter-generational connection.

Yan described it this way: "Although I would be seldom chatting with others, 'Oh! Did you play Pokémon GO?' would be asked, and the topic might continue with counting the number of Pokémon, ways of hunting and so on."

Victor commented, "I met John just because of this game, and we always went for Gym battles afterwards."

All participants expressed a common goal when playing was running, with the masses behaving in such a way to prevent any missing chance of hunting Pokémon. Tung said, "Suddenly, a kid 
shouted out that he caught the Snorlax. Afterwards, everyone nearby took out their phones to catch it at the same time."

Alex had a similar response: "When everyone plays, it seems you should follow the trend."

Most of the participants reflected that they shared a common goal amongst them, and it favoured a gathering together or reunion. Matilda felt it can establish better social skills to communicate with others: "When I'm studying nursing (degree program) and they're studying engineering (degree program), I totally didn't understand what they're talking about when discussing mechanics. However, Pokémon GO became a common topic among us."

Jason also indicated that "Normally you and your friends won't meet every night for dinner and stuff, but the game gave us a chance to say, 'Hey, wanna catch some Pokémon tonight?', 'Sure, let's go together. '”

The majority of the participants noted that a variety of age groups participated in this game. As a common goal, it generated communication and interaction among different generations, especially in the Chinese culture. Yan stated, "I felt communication with family increased, as I seldom talked with my mum when playing computer games. But sometimes when I returned home after playing Pokémon GO, my mum, who was playing this game, would ask, 'Where did you catch the Pokémon?"'

\section{- Stand on or lost}

All participants felt some potential negative impact might be resulted from playing the game if the players could not manage themselves well: examples like bumping into unaware obstacles in the street hurting themselves or others, social disturbance and addiction.

Sam recalled his experience of a hazardous condition, "Such as in Morse Park, many players rushed to the park to hunt for new species. But there may be some people playing football and they didn't know the players were rushing in, so that they may bump into the player..."

Tommy, Wilson, Jason, Sam, and Peter all reported that they had similar experiences as they reflected on their perceptions of the occurrence of accidents when players were focusing on hunting Pokémon: "crossed the road without looking", Tung and Yin said; "bumping into something or somebody"; and Victor stated, "took a wrong step".

Due to their enthusiastic involvement, Wilson recognised that one may disturb others when indulging in the game in public areas. He reported, "Many people had already blocked the road because of the appearance of Vaporeon. Then, I might feel that they seemed to really cause an obstruction."

Stephy had a similar response: "Some complaints towards us came from disturbing other's jogging activities, as joggers claimed that there would be nowhere for them to jog if many people were jammed in there."

Some conflicting opinions appeared concerning the lack of self-control of the players. Apart from mobility and improved sociability, John, a loyal fan of Pokémon GO, expressed, "Much money was spent compared with other games. During this time, a thousand dollars (US\$ 129) was spent swiftly like pouring water from a bucket, one splash and it's a lot of water. Also, lots of time was spent on the street; therefore, energy was lacking for doing other things. The state of exhaustion made me sleep immediately after I got back home."

Wilson also reflected that this uncontrollable behaviour affected his job performance: "We have been too concentrating on this game, obviously, our working efficiency was downgrading."

Tung had a similar response: "Some people might say it was too addictive or improper in time management, but I thought everyone could adjust by themselves."

\section{Discussion}

The LBG is an innovative game mode that could have positive effects on players' daily lives and could impact on their physical, psychological and cognitive well-being. Their childhood memories were the main reason that altered the participants' willingness and degree of involvement in the game. Pokémon was a popular cartoon in television series and movies from 1997 to 2002, which animated the stories of fantastic adventure between Ash Ketchum and his friends [58]. According to the game setting, all the elements were similar to the journey of Ash Ketchum, like encountering different Pokémon in different cities, battling with others in Gyms, etc [36,59]. Similar feelings and experiences could be achieved through Pokémon GO. Participants acknowledged that the game aroused them to recall significant Pokémon memories with advanced augmented reality technology and allowed them to becoming Pokémon trainers in the real world. Nine participants even claimed that such creation of Pokémon-related memories 
were more important than the game. This cognitive perspective was influencing them to be highly involved in creating a gaming experience that resulted in behavioural changes to fulfil the game requirements. Physical participation, community integration, and human interaction are the participating characteristics of LBG that could impact on health and well-being.

It is well known that the primary LBG game design is intended to activate the geolocation with certain physical movement with a GPS sensor [60]. In this study, the essential elements related to physical activity were 'walk and run' which matched the basic requirement for treasure-hunting. Subjectively, participants felt they wanted to "walk more" than before as it was favourable for hatching eggs or accessing other creatures by feet rather than by transportation. Aligning with studies of Howe et al. [45] and $\mathrm{Xu}$ et al. [61], participants reflected that their average daily steps increased in the range of 1,000-2,000 more than before playing the game. Ten participants might run to hunt a presenting Pokémon within a limited time or they might have unintentionally run with a majority of people who all shared the same aim of hunting a Pokémon. One participant of the study even sweated excessively after running, implying the raised level of physical activity. This finding was similar to another study that revealed that playing Pokémon GO increased the level of physical activity in moderate to vigorous ranges [43]. The findings promoted these insights: that daily physical activity could be maintained at high level if players could keep playing this game, such physical movement might act as an exercise habit in a daily routine; and the game could motivate those players to walk more than before. Nevertheless, other studies had differing perceptions and negative outcomes related to smartphone users including eye, musculoskeletal discomfort, etc [36,62-64].

A significant finding of this study was that the integration of community was established in the context of LBG design. The experience of participants was to explore unfamiliar places from the treasure-hunting feature, which is part of the aim and design of the LBG technology $[38,62]$. According to the responses of the participants, they reflected that they had motivation to go to somewhere they would seldom or never go as a result of a necessity to explore various places. While they kept going out into the community, they might consequentially get familiar to such surroundings. Moreover, it was evident that players could navigate the surrounding places rather than merely focusing on the screen when playing [62].

The human relationship could be strengthened throughout this game. The findings are similar to other studies in that the majority of LBG players responded that they were playing or moving in pairs or groups [38,62]. In the mode of gameplay, it could facilitate face-to-face social interaction instead of text-based communication in the electronic world. The participants focused on a common topic and goal more easily and without anxiety with others when receiving Pokémon information and battling at the same geolocation of Gyms. The players also initiated contact with strangers located around the geolocation while attempting to reach their common goal [62].

In the psychological aspect, the finding highlighted the trend of Pokémon GO to be fashionable for those who are fond of online games, and hinted that the bandwagon effect may exist in these conditions. The presence of a commonly played game might substantially influence the player's internal attitude and behavioural intention towards the game [63]. The variety of age groups that have been attracted to install this free-to-play game is due to the Pokémon upsurge. LBG is beneficial for maintaining a good relationship with players and their parents due to participating in this game. From the perspective of participants, it altered the generation gap and human relationship through sharing a common topic and goal. Moreover, the playing of LBG-Pokémon GO brought up childhood memories of the participants. The participants would recall, replay, indulge and finally practise in real life what they could remember, enjoy and retrieve from the past memories $[64,65]$. Another study indicated that by the sharing of a common and intentional goal among the participants could help to intensify their pursuit of the goal. [66].

Pokémon GO achieved record-breaking success globally based on shared memories and created a delightful Pokémon journey for many people. When huge numbers of people rushed into the street for the excitement of gameplay, some dangers and disturbances existed in the community. The study of Colley et al. [38] reported that players were usually distracted from their surroundings when immersed in the game, which meant they encountered an environmental influence involving collision, bumping and crossing the street without looking. 
All those game-related dangers were mentioned in the same way.

The findings revealed new phenomena such as, 'acting like in the real situation' and 'being connected'. All these explained a new communication and behavioural pattern between LBG players while playing at the same time or in the same place to pursue a common goal. Nevertheless, in the same way as other things, this is just like a double-edged sword, which can have both favourable and unfavourable consequences, depending upon how you use or control it yourself.

\section{Conclusion}

This focus group study explored new phenomena like visual appeal in a reality situation, social interaction and achievement, illustrated from the behavioural pattern and experience of playing LBG-Pokémon GO amongst young adults in Hong Kong. That this new phenomenon of playing LBG has a mix of benefits and risks is indubitable. The five main experiences of young adults playing LBG constructed a picture delineating physical and psychosocial perceptions of LBG game-play, including an innovative mode of gaming, walk to the next destination, virtual-reality navigator, link together, and stand on or lost. As health professionals, we never hear about the things that did not happen: myocardial infarction prevented through more exercise, blinking in the sunshine while hatching eggs. Most health mobile applications (app) can establish a business and health promoting platform that promote physical activity tend to change users who want to be healthy. Pokémon GO is not promoted as a health app, but players still end up doing a lot of walking or running for game playing. The possibilities for the app to create streets with an active, reclaimed playground for interconnected fun are boundless. Further studies of mobile games and LBG would facilitate the understanding of health changes related to the game-play experience and communities of all players.

\section{Conflict of Interest}

There are no conflicts of interest for all authors in this study.

\section{Author Contributions}

All authors have agreed on the final version and meet at least one of the following criteria [recommended by the ICMJE (http://www. icmje.org/recommendations/)]:

Substantial contributions to conception and design, acquisition of data, or analysis and interpretation of data;

Drafting the article or revising it critically for important intellectual content.

\section{References}

1. Andrew N. Smartphone vs. feature phone arms race heats up: which did you buy?. J. I. T3: 110-117 (2009).

2. Census and Statistics Department. Thematic household survey report no. information technology usage and penetration. Hong Kong Special Administrative Region (2015).

3. Liu F, Chen L, Chen H. Sustaining client relationships in the contract manufacturer own-brand building process: the case of a smartphone firm. Int. J. Bus. Manag. 6(1), 59-68 (2011).

4. U. S. Federal Communications Commission Annual report and analysis of competitive market conditions with respect to mobile wireless, including commercial mobile services; Federal Communications Commission (FCC): Washington, DC, USA (2010).

5. Telecommunication Industry Association Accessible mobile phone options for people who are blind deaf-blind, or have low vision; Telecommunication Industry Association
(TIA): Washington, DC, USA (2010).

6. Griffiths MD, Meredith A. Videogame addiction and its treatment. J. Contemp. Psycho 4(1), 247-253 (2009).

7. Johnson B, Hackett AF. Eating habits of 11-14-year-old schoolchildren living in less affluent areas of Liverpool, UK. J. Hum. Nutr. Diet 10(1), 135-144 (1997).

8. Loftus GR, Loftus EF. Mind at play; the psychology of video games. Basic Books, Inc (1983).

9. Millett CJ, Fish DR, Thompson PJ. A survey of epilepsy-patient perceptions of videogame material/electronic screens and other factors as seizure precipitants. Seizure 6(1), 457-459 (1997).

10. Peng W, Liu M. Online gaming dependency: a preliminary study in China. Cyberpsychol. Behav. Soc. Netw 3(1), 329-333 (2010).

11. Porter G, Starcevic V, Berle D, et al. (2010) Recognizing problem video game use. Aust. N. Z. J. Psychiatry 44(1), 120-128.

12. Quirk JA, Fish DR, Smith SJM, et al. Incidence of photosensitive epilepsy: a prospective national study. Electroencephalogr. Clin. Neurophysiol 4(1), 260-267 (1995).

13. Spence SA. Nintendo hallucinations: a new phenomenological entity. Irish J. Psychol. Med 2(1), 98-99 (1993).

14. Poli R. Internet addiction update: diagnostic criteria, assessment and prevalence. Neuropsychiatry 1(1), 04-08 (2017).

15. Herodotou C, Kambouri M, Winters N. The role of trait emotional intelligence in gamers' preferences for play and frequency of gaming. Comput. Human Behav 5(1), 1815-1819 (2011).

16. Ko CH, Liu GC, Hsiao SM, et al. Brain activities associated with gaming urge of online gaming addiction. J. Psychiatr. Res 43(1), 739-747 (2009).

17. Lemmens JS, Valkenburg PM, Peter J. Psychosocial causes and consequences of pathological gaming. Comput. Human Behav 1(1), 144-152 (2011).

18. Seay AF, Kraut RE. Project massive: Selfregulation and problematic use of online 
gaming. In Paper presented at the $\mathrm{CHI}$ 2007: proceedings of the ACM Conference on Human Factors in Computing Systems. CA, USA: San Jose (2007).

19. Wang ES, Chen LS, Lin JY, et al. The relationship between leisure satisfaction and life satisfaction of adolescents concerning online games. Adolescence 169(1), 177-184 (2008).

20. Chappell D, Eatough V, Davies M, et al. EverQuest-it's just a computer game right? An interpretative phenomenological analysis of online gaming addiction. Int. J. Ment. Health Addict 3(1), 205-216 (2006).

21. Griffiths MD. Diagnosis and management of video game addiction. N. Direct. Addict. Treat. Prevent 12(1), 27-41 (2008).

22. Lo SK, Wang CC, Fang WC. Physical interpersonal relationships and social anxiety among online game players. Cyberpsychol. Behav 1(1), 15-20 (2005).

23. Grohol J. Pokémon GO reportedly helping people's mental health, depression. PsychCentral (2016).

24. Schilling D. Is Pokémon GO the answer to American's obesity problem? Guardian 2016 Jul 13.

25. Griffin A. Pokémon GO: Trainer who became first in UK to catch 'em all lost two stone while doing so. Independent (2016).

26. University of Leicester. Press release: Pokémon GO could ease type 2 diabetes burden (2016).

27. Griffin A. Pokémon GO. Police rescue women from rough seas after they wade out in search of creatures. Independent (2016).

28. Morris S. Pokémon GO players rescued after getting lost in Wiltshire caves. Guardian (2016)

29. Dredge R, Gleeson J, Garcia XD. Presentation on Facebook and risk of cygberbullying victimisation. Comput. Hum. Behav 4(1), 16-22 (2014).

30. American Psychiatric Association (2013) Diagnostic and Statistical Manual of mental Disorders (DSM-5). American Psychiatric Association, Arlington, VA.

31. Ko CH, Yen JY, Yen CF, et al. The association between Internet addiction and psychiatric disorder: a review of the literature. Eur. Psychiatry 1(1), 1-8 (2012).

32. Young KS Internet addiction: the emergence of a new clinical disorder. Cyberpsycol. Behav 1(1), 237-244 (1998).

33. Kuss DJ, Griffiths MD Internet gaming addiction: a systematic review of empirical research. Int. J. Ment. Health Addict 2(1), 278296 (2012).
34. Gentile D Pathological video-game use among youth ages 8 to 18 : a national study. Psychol Sci 5(1), 594-602 (2009).

35. Orford J. Excessive appetites: a psychological view of the addictions. Wiley, USA (2001).

36. Juhász L, Hochmair HH. Where to catch 'em all? - a geopgraphic analysis of Pokémon GO locations. J. Geo-spatial. Inform. Sci 3(1), 241251 (2017).

37. Bowerman M. Children's hospital using Pokémon Go to get patients out of bed (2016).

38. Colley A, Thebault-Spieker J, Lin AY, et al. The geography of Pokémon GO: Beneficial and problematic effects on places and movement In Proceedings of the SIGCHI Conference on Human Factors in Computing Systems (2017)

39. Conditt J. Pokémon Go's mental health benefits are real. Engadget (2016).

40. Grohol J. Pokémon Go reportedly helping people's mental health, depression. Psych Central (2016).

41. Mulpeter K. Can Pokémon Go really improve your mental health? Fox News (2016).

42. Althoff T, White RW, Horvitz E. Influence of Pokemon Go on physical activity: Study and implications. J. Med. Internet. Res 18(12), e315 (2016).

43. Nigg CR, Mateo DJ, An J. Pokémon Go may increase physical activity and decrease sedentary behaviors. Am. J. Public Health 1(1), 37-38 (2017).

44. Wagner-Greene VR, Wotring AJ, Castor T, et al. Pokémon GO: Healthy or harmful?. Am. J. Public Health 1(1), 35-36 (2017).

45. Howe KB, Suharlim C, Ueda P, et al. Gotta catch'em all! Pokémon GO and physical activity among young adults: Difference in differences study. BMJ 355(1), i6270 (2016).

46. McCartney M. Game on for Pokémon GO. BMJ 354 (1-2), i4306 (2016).

47. School of Journalism and Communication the Chinese University of Hong Kong. Hong Kong internet use and online gamer survey (2011).

48. Chou C. Internet heavy use and addiction among Taiwanese college students: An online interview study. Cyberpsycho Behav. 5(1), 573585 (2011).

49. Haug S, Castro RP, Kwon M, et al. Smartphone use and smartphone addiction among young people in Switzerland. J. Behav. Addict 4(1), 299-307 (2015).

50. Hawi NS, Samaha M. To excel or not to excel: Strong evidence on the adverse effect of smartphone addiction on academic performance. Comput. Educ 98(1), 81-89 (2016).

51. Kebritchi M. Factors affecting teachers' adoption of educational computer games: a case study. BJET 2(1), 256-270 (2010).

52. Nagygyorgy K, Demetrovics Z, Urban R, et al. The development of the problematic online gaming questionnaire (POGQ). PloS. one (2012).

53. Sin NM, Talib O, Norishah TP, et al. Male students and digital game: Reason, motivation and feeling. IJIET 1(1), 6 (2014).

54. Van Rooij AJ, Schoenmakers TM, Vermulst $A A$, et al. Online video game addiction: Identification of addicted adolescent gamers. Addiction 1(1), 205-212 (2011).

55. Boyatzis R. Transforming Qualitative Information: Thematic analysis and code development. Sage, Thousand Oaks, CA (1998).

56. QSR NVivo. Version 11.0. QSR International Pty Ltd, Melbourne, Australia.

57. Richards $L$ Handling qualitative data: $A$ practical guide. Sage, Thousand Oaks, CA (2014).

58. Buckingham D, Sefton-Green J, Allison A, et al. Pikachu's global adventure: The rise and fall of Pokémon. Duke University Press (2004).

59. Niantic Pokémon GO. The Pokémon company (2016).

60. Benes SJ, Downing L, Gutowski GJ. U.S. patent no. $6,756,882$. Washington, DC: U.S. Patent and Trademark Office (2004).

61. Xu H, Xian Y, Xu H, et al. Does Pokémon Go help players be more active? An evaluation of Pokémon Go and physical activity. Circulation 1(1), A02 (2017).

62. Jungselius $B$, Weilenmann A, Rost $M$. Pokémon GO and mobile wellbeing: Initial observations on experiences and reported connection (2016).

63. Kim J, Gambino A. Do we trust the crowd or information system? Effects of personalization and bandwagon cues on users' attitudes and behavioural intentions toward a restaurant recommendation website. Comput. Human Behav 65(1), 369-379 (2016).

64. Weertman A, Arntz A. Effectiveness of treatment of childhood memories in cognitive therapy for personality disorders: a controlled study contrasting methods focusing on the present and methods of focusing on childhood memories. Behav. Res. \& Therapy 45(1), 2133-2143 (2007).

65. Thompson WC, Aspinall P, Montarzino A. The childhood factor: Adults visits to green places and the significance of childhood experience. Environ \& Behav. 40(1), 111-43 (2008).

66. Shteynberg G, Galinsky AD. Implicit coordination: Sharing goals with similar others intensifies goal pursuit. J. Experiment. Soc. Psychol 47(1), 1291-1294 (2011). 